\title{
ONLINE HEALTHCARE: INTERNET PHARMACIES MAY NOT ALWAYS BE GOOD FOR YOUR HEALTH
}

\author{
Carlisle George \\ Middlesex University, United Kingdom,c.george@mdx.ac.uk
}

\begin{abstract}
Rapid developments in information and communication technologies (ICT) have resulted in the widespread use of the Internet as an important medium for commercial activity. Such activity commonly referred to as electronic commerce, or e-commerce has facilitated new business models in many different commercial endeavours including pharmaceutical and medical practice. This paper investigates the growing phenomenon of drugs sales and medical services over the Internet via Internet Pharmacies. Although Internet Pharmacies have resulted in many benefits to consumers, there are serious health and safety concerns about various aspects of this commercial activity, especially where laws and regulations are not adhered to. Such concerns raise important issues regarding social accountability when using ICT to facilitate the provision of medical services. The paper examines the benefits and problems associated with Internet pharmacies with a view to discussing some of the challenges faced especially by legislators and regulators. It argues that many of these challenges are compounded by the nature of the Internet itself, social and economic realities, different national regulatory structures and the difficulty of enforcing national laws outside of legal jurisdictions. Finally it discusses how some of the present challenges may be addressed.
\end{abstract}

\section{INTRODUCTION}

The Internet provides a new and exciting medium for doing business, with many advantages over the traditional physical marketplace. The physical marketplace has become the 'marketspace' which is free from physical restrictions, making commerce available almost everywhere and at 
all times ${ }^{1}$. This new medium also offers universal technical standards, global reach, interactivity, personalisation and customization, among other capabilities ${ }^{2}$.

The many advantages of the Internet, however, are counterbalanced by many problems especially with regard to effective regulation. E-commerce brings new challenges to regulators mainly due to new possibilities with digital technology and its ability to transcend traditional legal jurisdictions. The commercial availability of drugs on the Internet (sold via Internet Pharmacies ${ }^{3}$ ) has resulted in many benefits to consumers. There are, however, serious health and safety concerns about various aspects of this commercial activity, especially were laws and regulations are adhered to.

This paper first examines the legal classification of drugs which determines how they are sold. It then gives an overview of Internet Pharmacies followed by a discussion of the benefits and problems which they bring. The paper ends by discussing the challenges ahead for regulators and suggests possible ways of addressing these challenges.

\section{DRUG SALES ON THE INTERNET}

Consumers have legal access to drugs/medications usually by either two or three mechanisms depending on the country of sale. In the UK, three mechanism exists: (i) A consumer needs a prescription issued by a licensed health care professional, ${ }^{4}$ to purchase drugs classified as 'prescription-only drugs. ${ }^{5}$ These drugs must be dispensed by a pharmacist in licensed premises; (ii) for certain drugs called 'pharmacy-only drugs' a prescription is not required but a pharmacist must be consulted before purchase; ${ }^{6}$ (iii) otherwise

${ }^{1} \mathrm{~K}$, Laudon and C, Traver, Ecommerce: business, technology, society. Addison Wesley 2002

${ }^{2}$ Ibid

${ }^{3}$ Pharmacies which offer medicines (or pharmaceutical products) for the sale or supply over the internet or otherwise makes arrangements for the supply of such products over the internet.

${ }^{4}$ In the UK until 1992, only doctors and dentists were allowed to prescribe. However, the Medicinal Products: Prescription by Nurses Act 1992, further allowed certain specially qualified health visitors and nurses to prescribe.

${ }^{5}$ Listed in The Prescription-Only Medicines (Human Use) Order 1997

${ }^{6}$ There is no statutory list of such drugs. Any medicine which is not prescription only or general sales list, is pharmacy only. 
a consumer can purchase drugs classified as 'general sales list' drugs which do not require a prescription.?

In the US, drugs are classified into two categories namely prescription drugs and over-the-counter drugs. Two mechanisms for buying drugs exists: ${ }^{8}$ (i) prescription drugs must be purchased with a valid prescription; and (ii) over-the-counter drugs, do not require a prescription nor a consultation with a pharmacist. In this paper, the term 'prescription drugs' will be used to mean drugs requiring a prescription before sale. This includes the UK classification of 'prescription-only drugs'.

\section{INTERNET PHARMACIES - AN OVERVIEW}

The widespread use of the Internet as a medium of information, communication and commercial activity inevitably resulted in the selling of prescription drugs online (since January 1999) by businesses called Internet pharmacies. ${ }^{9}$ An Internet pharmacy is also referred to by various other names such as an online pharmacy, cyberpharmacy, ePharmacy and virtual pharmacy/drugstore. ${ }^{10}$ For purposes of this paper, the term 'Internet pharmacy' refers to the all the terms above.

Generally, Internet pharmacies sell a variety of products (e.g. for health, beauty) in addition to prescription drugs. They vary significantly in type and mode of operation and have been categorized into various types. One useful categorization focuses on the mechanism for dispensing/selling medications and distinguishes between three types namely: "(i) pharmacies which dispense drugs only with a valid prescription; (ii) pharmacies that provided online consultations (in place of a physical examination by a physician) for prescribing and dispensing medicines; and (iii) pharmacies that dispense medications without a prescription.

${ }^{7}$ Listed under The Medicines (Products other than Veterinary Drugs)(General Sales List) Order 1984.

${ }^{8}$ E, Brass. Changing the Status of Drugs from Prescription to Over-the-Counter Availability. N Engl J Med, Vol. 345, No 11. September 13, 2001.

${ }^{9}$ S. Crawford, Internet Pharmacy: Issues of Access, Quality, Costs and Regulation. Journal of Medical Systems, Vol.27, No.1, Feb 2003. Also see Supra 3

${ }^{10} \mathrm{Ibid}$

${ }^{11}$ C. Radatz, Internet Pharmacies, Wisconson Briefs, Brief 04-5, March 2004. http://www.legis.state.wi.us//rb/pubs/wb/04wb5.pdf 


\subsection{US Internet Pharmacies}

The US has had a long history of delivering medical and pharmacy services over long distances and this has continued to develop with technology. ${ }^{12}$ Widespread use of the telephone in the 1870's enabled 'pharmacy-based telephone services', whereby pharmacies were able to directly communicate and exchange information with patients' physicians. ${ }^{13}$ Also by the mid $20^{\text {th }}$ century, patients used the telephone to obtain medical attention from their physicians. ${ }^{14}$

As early as 1872 , Americans began purchasing goods via mail order, after the world's first general merchandise mail-order company was started in the US by Aaron Montgomery Ward. ${ }^{15}$ Since then mail-order has been used to purchase almost every consumer product including prescription drugs. ${ }^{16}$ Generally mail-order pharmacies have provided drugs at a lower cost (especially for patients on long term prescriptions) than retail pharmacies.

With the advent of the Internet along with its many advantages (e.g. global reach, advertising potential), the traditional 'mail order' drug business model (which still exists) was extended to the online electronic business model. This led to the first major online/Internet pharmacy, 'Soma.com', which began operations in the US in January $1999^{17}$ (it has since been bought by the large US drugstore chain CVS and is now CVS.com). Soma.com was followed by other well known and reputable Internet pharmacies such as PlanetRx.com (which is now closed) and Drugstore.com. ${ }^{18}$ Since then numerous Internet Pharmacies sites have surfaced.

In order to purchase prescription drugs, a potential purchaser first opens an account with the pharmacy which involves giving credit and insurance information. The potential purchaser must then submit a valid prescription (via fax, email, or his/her doctor can send it directly to the pharmacy) which is verified (for integrity) before dispensing. After payment and dispensing of the medication it is then sent either via mail, courier or picked up from a

${ }^{12}$ S. Kahan, A. Seftel and M. Resnick, Sildenafil and the Internet. The Journal of Urology. Vol. 163, 919-923, March 2000.

${ }^{13}$ Ibid

${ }^{14}$ Ibid

$15 \mathrm{http://www.graveyards.com/rosehill/ward.html}$

${ }^{16}$ Mail-order pharmacies are not legal in all US states, e.g. in Michigan state law prohibits mail-order pharmacies.

${ }^{17}$ Supra 9

${ }^{18} \mathrm{Ibid}$ 
local drugstore. Usually, the Internet pharmacy enables the purchaser to communicate with the pharmacist (e.g. ask questions about their medication) via email or telephone.

\subsection{UK Internet Pharmacies}

The first British Internet pharmacy was Pharmacy2u.co.uk which began online operations on November 22, 1999. ${ }^{19}$ Pharmacy2u.co.uk was inspired by the Internet pharmacy model existing at that time in the US and was adapted for the UK market. ${ }^{20}$ It is operative to date and its services include dispensing and delivering private prescriptions, as well as selling various medical, healthcare, and beauty products among others.

Strict protocols were specially adapted for the sale of medicines over the Internet in the UK. For general pharmacy medicines (i.e. not requiring a prescription) a potential purchaser must choose the desired product(s) then complete an online questionnaire. The pharmacist will then examine the questionnaire and decide either: to allow the sale; or to refer the potential purchaser (via email) to visit a local pharmacy or doctor. To purchase prescriptions-only medicines, first a potential purchaser needs to register in order to submit his/her prescription details so as to receive price quotes via email. Once a price is agreed, the potential purchaser needs to send his/her prescription to the pharmacy, which then dispenses the medicine and delivers it to the purchaser.

\section{BENEFITS}

Use of the Internet to sell drugs has resulted in many benefits to consumers. ${ }^{21}$ In a June 2000 US study conducted by Forrester Research, ${ }^{22}$ consumers gave the following motivating factors for buying prescription drugs from online pharmacies: order during off hours $(59 \%)$; saves time $(50 \%)$; easier than mail order $(50 \%)$; cheaper $(44 \%)$; cuts trip to the drug store $(41 \%)$; refill reminders $(26 \%)$; online medication information $(23 \%)$;

${ }^{19}$ Britian's first Internet pharmacy opens. The Pharmaceutical Journal, Vol 263, No 7073, p849, Nov, 27, 1999.

${ }^{20}$ Ibid

${ }^{21}$ Statement of William K. Hubbard, Associate Commissioner for Policy and Planning before The Committee on Government Reform U.S. House of Representatives Hearing on Internet Drug Sales, March 18, 2004. http://www.fda.gov/ola/2004/internetdrugs0318.html

22 C. Fung, H.Woo and S. Asch, Controversies and legal Issues of Prescribing and Dispensing Medicines Using the Internet, Mayo Clinic Proc. 2004; 79: 188-194 
customer service (20\%). In 2003, a survey by the UK The National Audit Office, found that consumers were buying prescription medicines online because it was easy to obtain (without a prescription) and cheaper. ${ }^{23}$ The following sections further explores some of the benefits of buying drugs online.

\subsection{Ease, Convenience and Increased Choice}

Prescription drugs are now accessible on a twenty-four hour basis, resulting in shopping convenience especially for the disabled people in remote areas and those who have difficulty travelling to a pharmacy. ${ }^{24}$ The Internet also makes available a wide selection of pharmaceutical products giving consumers increased choice, and allowing them to easily compare prices and check availability of medications.

\subsection{Increased Consumer Information and Information Exchange}

Consumers can access a huge amount of medical information (provided by Internet pharmacies) which may help them better understand issues related to health and treatment. This may have an effect of loosening the grip of the professions and increasing patient autonomy. Consumers can investigate issues such as the effectiveness of different drugs, side/adverse effects of medications, new and alternative treatments among others. ${ }^{25}$ In some cases patients are also able to check and verify the advice and treatment they receive from their doctors. ${ }^{26}$ One small study comparing Internet and community pharmacies in the US concluded that in general more comprehensive information on drugs were provided by Internet pharmacies, although they were slower to respond. ${ }^{27}$ In addition to information on drugs and treatment, Internet pharmacies facilitate the reporting (by patients) of adverse drug effects and reactions ${ }^{28}$ and allow

${ }^{23}$ NAO. Safety, quality, efficacy: regulating medicines in the UK, $16^{\text {th }}$ Kan 2003 http://www.nao.uk/publications/nao reports/02-03/0203255.pdf

${ }^{24}$ Consumer advice: buying drugs online. Harv Health Lett. June 2000; 25: 1-3.

${ }^{25} \mathrm{~J}$. Henney. Cyberpharmacies and the role of the US Food and Drug Administration. J Med Internet Res. 2001; 3(1):E3

${ }^{26}$ A study reported in the British Medical Journal, 6 March 2004 (p564) concluded that some cancer patients were able to use the Internet verify their treatment and advice, which helped them to better understand their illness.

$27 \mathrm{M}$, Wagner, J, Alonso and A, Mehlhom. Comparison of Internet and community pharmacies. Ann Pharmacother, 2001; 35; 116-119.

${ }^{28} \mathrm{~S}$. Zeman. Regulation of Online Pharmacies: a case for cooperative federalism. Ann health Law, 2001; 10:105-137. 
pharmacists to easily send reminders to patients to adhere to their medications. ${ }^{29}$

\subsection{Privacy and Anonymity}

Use of the Internet can afford privacy to consumers who may not want to shop in a public place. Anonymity on the Internet may also allow consumers to ask questions regarding medications and treatments, which they may otherwise be embarrassed to ask in public. ${ }^{30}$

\subsection{Generally Cheaper Costs}

In many instances online prescription drug sales have resulted in cheaper drugs and medicines for consumers. For example, many US residents reimport drugs into the US from Canada, due to lower prices which can be up to $70 \%$ cheaper. ${ }^{31}$ This has led to drug sales from Canadian pharmacies (reported in March 2004) at an estimated value of US\$1billion..$^{32}$ Generally, the cost of drugs are lower in Canada, due to the regulation of drug prices (unlike in the US) and patent laws which make it easier to market generic versions of brand names. ${ }^{33}$ Even within the US, due to marketplace competition prescription, drugs are cheaper when bought online. ${ }^{34}$ A 2001 US study comparing prices in Internet pharmacies with retail chain drugstores found that drugs for Parkinson's Disease was 7-58\% cheaper for brand name drugs and $31-78 \%$ cheaper for generic drugs. ${ }^{35} \mathrm{~A}$ few previous surveys, however, have found instances where certain drugs purchased online were not cheaper especially when shipping and handling costs were added to advertised prices. ${ }^{36}$

${ }^{29}$ Drug and biotechnology news: patients to control health with help of Internet pharmacy. Med Ind Today. January 71999.

${ }^{30}$ Supra 22

${ }^{31}$ M. Korcok, Internet Pharmacy: the tug-of-war intensifies. JMAC, 16 March, 2004.

${ }^{32}$ Ibid

${ }^{33}$ Buyinsg Rx Drugs Online, Financial Awareness Bulletin, Vol. XII, No. 2, October 2003.

http:/www.neamb.com/memsrvcr/communications/articles/102003 fab.jsp

${ }^{34}$ Supra 27

${ }^{35} \mathrm{Ibid}$

${ }^{36}$ Example see W.Weber, Austrian survey shows hazards of internet prescription drugs. The Lancet, Vol 356, No 9236, 30, Sept 2000; 


\subsection{Availability of Alternative Treatments}

The licensing of drugs can a very slow process (due to testing requirements). The Internet, however, can facilitate access to non-licensed drugs which patients with terminal illness (e.g. Cancer, AIDS) may be willing to use on an experimental basis. This may be beneficial in some cases, for example, where a drug has been licensed and used successfully in one country but has not been licensed in another country. Patients who have exhausted other avenues of treatment can gain access to this drug.

\section{PROBLEMS}

In many cases Internet pharmacies engage in activities which may expose patients and consumers to risks. Many of these activities also have legal implications. Some of the more important concerns are discussed below.

\subsection{Online Prescriptions Without Prior Physical Examination by Doctor}

Many online pharmacies operate by giving an online consultation, which requires a customer to fill out a general questionnaire online. This is then evaluated (reportedly by a physician affiliated to the pharmacy) in order to issue a prescription, and dispense drugs. The use of prescription drugs without prior examination in person by a healthcare practitioner can be very dangerous. Also, without further supervision/monitoring (by a healthcare professional) there may be no way of determining whether a particular drug treatment is effective.

Online consultations assume that questionnaires are completed truthfully and therefore run the risk of prescribing medications on false information. The absence of a prior physical examination by a qualified healthcare professional can result in misdiagnosis or drug interaction among other problems. ${ }^{37,38}$ Patients also run the risk that a legitimate consulting physician may not exist to evaluate the online questionnaire. Furthermore, use of general questionnaires may not provide the necessary information for the determination of a number of important issues such as whether a particular

\footnotetext{
${ }^{37}$ J, Henny, Online Pharmacies - Maintaining the Safety Net. Medscape Pharmacists 1(1), 2000.

${ }^{38}$ Contrary to the generally held opinion, one study reported that Internet prescribing for Viagra was safe and effective. See. M. Jones, Internet-bases Prescription of Sildenafil: $A$ 2104-Patient Series. Journal of Medical Internet Research, 2001; 3(1): e2
} 
drug: ${ }^{39}$ (i) will work for an individual; (ii) is safe to use; (iii) is more appropriate than another treatment; (iv) may cause adverse reactions if an individual is taking another medication; or (v) may be harmful due to an underlying medical condition such as an allergy.

In some cases, doctors who issue online prescriptions (cyberdoctors) are either not licensed to practice medicine in the consumer's state/country or are not credible. A US study (October 2003) into the background of cyberdoctors, found that most either: ${ }^{40}$ had financial problems; were sued for malpractice, had their licence revoked or were recovering from drug addiction. Another 2003 US study reported that many cyberdoctors recruited by Internet Pharmacies were previously unemployed, semi-retired or had declining practice incomes. ${ }^{41}$

The writing of prescriptions via online consultation may raise important legal issues especially related to confidentiality and civil liability for medical malpractice should something go wrong. ${ }^{42}$ Confidentiality issues may arise because information given for online consultations may be prone to be seen by people other then the consulting doctor, unless strict security and protocols are in place. ${ }^{43}$ Civil liability issues may arise since liability for malpractice may not be clearly established where an online prescription is issued. This is because whereas in a traditional doctor-patient relationship a clear duty of care exists, it is debatable whether a doctor who prescribes medication online (without any direct verbal or physical contact with a patient), forms a doctor-patient relationship and therefore attracts a duty of care. $^{44}$

\subsection{Dispensing Prescription Drugs Without a Prescription}

A large number of online pharmacies have been found to dispense prescription drugs without a prescription. ${ }^{45,46}$ Well documented examples

${ }^{39}$ Offers to Treat Biological Threats: What You Need to Know. Federal Trade Commission, Consumer Alert. October, 2001. http://www.ftc.gov/bcp/conline/pubs/alerts/bioalrt.htm

40 Beau Dietl Conducts Investigation Into Internet Prescription Drug Scams. October 2003.

http:/www.investigations.com/bd news_ $10-03 . \mathrm{htm}$

${ }^{41}$ Supra 9

${ }^{42}$ Supra 12

${ }^{43}$ Ibid

${ }^{44}$ Ibid

${ }^{45}$ Employers urged to monitor access to Internet Pharmacies. Workplace Subst Abuse Advis. $2002 ; 16(14)$. 
include the selling of sildenfil (Viagra) and ciprofloxacin (an antidote for anthrax). ${ }^{47,48}$ In 1999 a US research study reported up to $19 \%(9 / 46)$ of Internet Pharmacies not requiring a prescription or consultation by a health care professional before dispensing. ${ }^{49}$ In 2000 a study by the US General Accounting Office reported up to $13 \%$ (25/190) dispensing medications without prescriptions..$^{50}$ In 2004 the National Centre on Addiction and Substance Abuse (Columbia University), identified 496 web sites selling controlled prescription drugs: $99 \%$ did not require a prescription (41\% stated that no prescription was needed and $49 \%$ used online consultation with a questionnaire). ${ }^{51}$ In the UK, the National Audit Office (2003) reported that 1 in 100 people were buying prescription medicines on the Internet (without a prescription) for various conditions such as obesity, prostate cancer, hair loss, or erectile dysfunction. ${ }^{52} \mathrm{~A}$ study by WHICH ONLINE, published in March 2004, reported that researchers were able to buy various prescription drugs (e.g. Seroxat - antidepressant, Xenical - for fat absorption, Reductil for weight loss) on UK Internet sites without prescriptions. ${ }^{53}$

The dispensing of drugs without a prescription can have serious implications for consumers such as adverse drug effects, and the various dangers identified in the previous section. Another potential danger of dispensing prescription medicines without a prescription is that such medicines can fall into the wrong hands such as: people addicted to medication; people who have misdiagnosed themselves; people who may not be suitable for a particular medication; and even children. This is illustrated by the following examples given below.

${ }^{46}$ For example various prescription-only drugs are offered for sale (August 2004) without a prescription at the 'OffShore Pharmacy'. http://smart-drugs.net/index.html

${ }^{47}$ Expanded reporting: anthrax: study finds outbreak of cipro web sites followed mail attacks. Med Lett CDC \& FDA. October 9, 2002.

http://www.obgyn.net/newsheadlines/headline medical news-Anthrax-20021009-0.asp

${ }^{48}$ E. Gursky, T. Inglesby and T, O'Toole, Anthrax 2001: Observations on the Medical and Public Health Response. Biosecurity and Bioterrorism: Biodefence Strategy, Practice and Science, Volumel, Number 2, 2003.

$49 \mathrm{~B}$. Bloom, and R. Iannacone. Internet availability of prescription pharmaceuticals to the public. Ann Inter Med. 1999; 131:830-833.

${ }^{50}$ US General Accounting Office. Internet pharmacies - Adding Disclosure Requirements Would Aid State and Federal Oversight. Washington, DC: October 2000. Publication GAO-01-69. http://www.gao.gov/new.items/d0169.pdf

51 National Center on Addiction and Substance Abuse at Columbia University. You've got drugs! Prescription drug pushers on the Internet. February 2004. http://www.casacolumbia.org/pdshopprov/files/you ve got drugs.pdf

52 Supra 23

${ }^{53}$ WHICH ONLINE, Internet Pharmacies fail our medical as Computing Which? Investigates the sale of prescription only medicines online. WHICH ONLINE, March 2004. http://sub.which.net/ict/reports/mar2004co6t7/01 frontpage.jsp 
In 2001, a young UK (London) male drug abuser committed suicide after suffering from a drug addiction. ${ }^{54} \mathrm{He}$ had bought large amounts of drugs (painkillers, tranquillisers and antipsychotics ${ }^{55}$ ) over the Internet. An inquest into his death reported that at one point he was receiving 300 anti-depressant tablets in the post every day at his East London home and that he had tried 23 types of prescription drugs. ${ }^{56,57}$ In 2002, a 40 year old UK (Birmingham) male (who had an undiscovered heart condition), collapsed and died after taking Viagra purchased from the Internet but not prescribed by his physician. ${ }^{58}$ In a 2003 briefing to the US Congress, an investigator reported that his children were able to order prescription drugs online..$^{59}$ His 9 year old daughter ordered a prescription weight-loss drug on the US Drug Enforcement Administration (DEA) Controlled Substance list and his 13 year old son ordered and received Prozac (a drug on the US Food and Drug Administration's (FDA) Import Alert list). ${ }^{60}$

The selling of prescription drugs without a prescription is a clear breach of medical ethics and of laws in the UK and US. Such practices also attract potential criminal and civil liability against pharmacies. Product liability issues may also arise since normally when drugs are prescribed by a physician, under the 'Learned Intermediary Doctrine', the prescribing physician and not the drug manufacturer has a duty to give adequate warning to patients $^{61}$. If no prescribing physician is involved in the sale of prescription drugs, then either the pharmacy or manufacturer may be liable for any harm suffered. Some Internet pharmacies have addressed this problem by requiring that purchasers agree to a waiver of liability for any harm caused by products sold. A 2004 UK study found that $41 \%$ of Internet pharmacies surveyed issued such waivers ${ }^{62}$. This practice clearly violates unfair contracts legislation.

${ }^{54} \mathrm{M}$. Thompson, Buying medicines one the world wide web: what is legal and what is not? The Pharmaceutical Journal, Vol 271 No 7262, p202.

${ }^{55}$ Antipsychotics are prescription-only drugs used to symptoms of schizophrenia and other kinds of psychosis.

${ }^{56} \mathrm{~A}$. Barnett, Deadly cost of the trade in online prescription drugs. The Observer Sunday August 10, 2003. http://observer.guardian.co.uk/drugs/story/0,11908,1015880,00.html

${ }^{57}$ T. Mangold \& S. Hann. Online Pharmacies: the Poisoned Pill. 2002

http://www.readersdigest.co.uk/magazine/pharmacies, htm

${ }^{58} \mathrm{Ibid}$

${ }^{59}$ S. Lueck, Drug Industry Enlists An Ex-Cop Lobbyist. The Wall Street Journal. Oct 22, 2003.

${ }^{60} \mathrm{Ibid}$

${ }^{61}$ Supra 12

${ }^{62}$ Supra 53 


\subsection{Purity and Quality of Drugs}

Drugs sold in any country must meet the required quality and safety standards set by the law of that country. A major concern when buying drugs on the Internet is the purity/quality of the drugs purchased. In May 2004, a study which evaluated the risks of importing drugs into the US concluded that many drugs imported through the Internet were: ${ }^{63}$ past their expiry date; sub-potent or above potency indicated; contained the wrong dosage; contaminated or counterfeit; and not stored/shipped properly, among other problems.

When purchasing drugs online consumers have no way of knowing the origins of a particular drug, or where it was manufactured and hence it may be impossible to verify the quality of the drug. The May 2004 report also found that many drugs which claimed to be manufactured under FDA guidance or sent from Canadian pharmacies were manufactured in other countries such as China, Pakistan, Thailand, India, the Islamic Republic of Iran and Singapore. ${ }^{64}$ Random inspection visits to various mail ports reported evidence such as: ${ }^{65} 88 \%$ (1019/1153) of drugs examined were not FDA approved and were sent from countries such as Thailand, India and the Philippines; 87\% (1728/1982) of drugs examined were not FDA approved and were sent from Mexico; antibiotics were two years past their expiration date.

The quality/purity of drugs is an important issue since consumers can be affected either directly by harmful drugs or indirectly by their condition getting worse due to ineffective drugs. ${ }^{66}$

${ }^{63}$ Giuliani Partners LLC, Examination and Assessment of Prescription Drug Importation from Foreign Sources to the United States. Interim Findings, May 11, 2004. http://www.heartland.org/pdf/14978.pdf

${ }^{64}$ Ibid

${ }^{65}$ Ibid

${ }^{66}$ Buying Drugs over the Internet. Its your health. May 2003.

http://www.hc-sc.gc.ca/english/pdf/iyh/buying_drugs_internet.pdf 


\subsection{Counterfeit Drugs}

The sale of counterfeit ${ }^{67}$ drugs via the internet presents a very worrying prospect. For example in February 2004, The New England Journal of Medicine, reported several web sites selling contraceptive patches (under the brand name "Ortho Eva"), which did not contain any active ingredient. ${ }^{68}$ In the US, counterfeiters have mainly targeted expensive drugs such as. ${ }^{69}$ injectables (e.g. Procrit, used to help the body make red blood cells and used to treat anemia associated with kidney disease); treatments for HIV and AIDS (e.g. Neupogen, which promotes the growth of white blood cells which help to fight infections); psychiatric medications (e.g. Zyprexa - used to treat schizophrenia) and other popular drugs such as Viagra (which increases the ability for the body to maintain an erection). In 2004 reports of fake versions of drugs imported into the US included Viagra, Accutane acne treatment and OxyContin painkiller. ${ }^{70}$ In 2003 the FDA estimated that $10 \%$ of the global medicines market were counterfeit and that over US\$32 Billion was being earned annually from the sale of counterfeit and substandard medicines. ${ }^{71}$

\subsection{Foreign Labels and Different Drug Names}

The importation of drugs manufactured or sold in a foreign country may pose problems and risks to consumers. Different countries have different drug labelling requirements. ${ }^{72}$ This means that a drug produced/marketed for sale in one country and sold in another may be misbranded (i.e. not meeting the requirements of the second country) and therefore illegal. In addition

67 "Counterfeit medicines are part of the broader phenomenon of substandard pharmaceuticals. The difference is that they are deliberately and fraudulently mislabeled with respect to identity and/or source. Counterfeiting can apply to both branded and generic products and counterfeit medicines may include products with the correct ingredients but fake packaging, with the wrong ingredients, without active ingredients or with insufficient active ingredients".

World Health Organisation, Fact Sheet No 275, Nov. 2003. http://www.who.int/mediacentre/factsheets/2003/fs275/en/

${ }^{68}$ P. Rudolf, and I, Bernstein, Counterfeit Drugs, N Engl J Med 350; 14, April 1, 2004.

${ }^{69} \mathrm{Ibid}$

${ }^{70} \mathrm{~K}$. Dooley, Online pharmacies shipped fake drugs to U.S., report says., Bloomberg News, Thurs 17 June, 2004. http://the.honoluluadvertiser.com/article/2004/Jun/17/bz/bz10a.html

${ }^{71}$ Supra 67

72 H, Waxman, Prescription Drugs with foreign labels. October 11, 2000 http://216.239.59.104/search?q=cache:270iM3 Kw7cMJ:www.house.gov/reform/min/pdfs /pdf inves/pdf prescrip loop rep.pdf+Prescription+Drugs + with +foreign+labels.\&hl=en 
foreign labels may result in the following problems: ${ }^{73}$ Labels may be in a different (foreign) language which consumers may not understand; drugs may be sold under different names in different countries (e.g. An ulcer medication named Prilosec in the US is sold as Losec in Canada); Label identification numbers may be different according to country (e.g US drug labels have a National Drug Code Number and Canadian drug labels have a different Drug Information Number); Labels may have different indications and instructions according to country (e.g. the US and Canadia have slightly different dosage instructions for the anticonvulsant drug called Dilantin).

\subsection{Availability of Unapproved or Illegal Substances \& Fraudulent Products}

The Internet has been used to promote the use and sale of many unapproved substances (including narcotic ${ }^{74}$ and psychotropic ${ }^{75}$ drugs, designer drugs ${ }^{76}$, banned drugs and fraudulent products). ${ }^{77}$ In some cases a drug may be licensed for a particular use, however, some web sites may suggest uses other than what it is licenced for. ${ }^{78}$ In other cases a drug may be a prescription drug in one country but can be ordered online without a prescription. ${ }^{79}$ Yet in other cases a drug may be banned or unlicensed in one country but is obtainable online ${ }^{80}$ Many sites sell nootropics/'smart drugs ${ }^{81}$ (e.g. Piracetam ${ }^{82}$ and Hydergine ${ }^{83}$ ) which claim to enhance cognitive abilities

${ }^{73}$ Ibid

${ }^{74}$ Narcotic drugs are those which produce numbness or stupor. They are often taken for pleasure or to reduce pain, and prolonged use can lead to addiction (e.g. Cocaine).

75 Psychotropic drugs affect the mind or mood or other mental processes e.g. Diazepam (valium)- a sedative and muscle relaxant; Alprazolam (xanax)- an anti-anxiety agent. These drugs are controlled under The United Nations Convention on Psychotropic Substances, 1971.

${ }^{76}$ Designer drugs are derived from making minor alterations of approved drugs in an effort to circumvent legal restrictions. They are intended for recreational use to give hallucinogenic experiences. (e.g. KAT, Special K, Cloud 9, Sextasy-Viagra combined with Ecstasy).

http://northport.k12.ny.us/ nms/masih/desdrugs.html

http://ncaddoc.org/atod-pages/dsgnr-drugs.htm

${ }^{77}$ M. Childs, L.Ellison and D. Prayle. Drugs and the Internet. New Law Journal, Vol 148, No 6868, p 1840, 11 Dec 1998.

${ }^{78}$ Ibid

${ }^{79}$ The International Narcotics Control Board Annual report (released March 2004, stated that in some Internet pharmacies nearly $90 \%$ of the orders were for internationally controlled substances such as hydrodone, diazepan and alprazolam.

${ }^{80}$ During a investigation by $\mathrm{BBCl}$ (reported in May 2004) the date-rape- drug Rohypnol was purchased on the Internet at $£ 60$ per tablet and shipped from Thailand.

http://www.netdoctor.co.uk/news/index.asp?id $=111455 \& \mathrm{D}=14 \& \mathrm{M}=5 \& \mathrm{Y}=2004$

${ }^{81}$ For comprehensive coverage of smart drugs see: http://www.damicon. $\mathrm{fi} / \mathrm{sd} /$

${ }^{82}$ See: http://www.ceri.com/noot.htm 
(e.g. memory boosting ${ }^{84}$ ). Other sites sell 'wonder drugs' such as growth hormone ${ }^{85}$ and melatonin. Yet others sell 'miracle cures' and fraudulent treatments. For example, in 2000 the Federal Trade Commission (FTC) of the US took action against several companies whose web sites offered fraudulent products for sale. ${ }^{86}$ Among claims made were: a cure for arthritis with a fatty acid derived from beef tallow; and a treatment for cancer and AIDS with a Peruvian plant derivative. ${ }^{87}$

Cyber trafficking in unapproved substances is highly detrimental to consumers both in terms of the financial costs and the potential danger to their health. These activities are also contrary to international law such as the 1971 United Nations Convention of Psychotropic Substances. ${ }^{88}$ In its 2003 Annual Report dated $3^{\text {rd }}$ March 2004, the International Narcotics Control Board (INCB), highlighted the increase in cyber trafficking of pharmaceutical products containing internationally controlled substances (e.g. narcotic or psychotropic substances) ${ }^{89}$. This problem may therefore continue to increase more pharmacies appear online.

\subsection{Medical and Financial Privacy Concerns}

The US Federal Trade Commission, in its July 2000 report, identified that many US based Internet pharmacies were not adhering to their assurances on privacy and confidentiality ${ }^{90}$. Furthermore many of them did not even post privacy policy statements. This situation continues to be the case in 2004. ${ }^{91}$ In July 2004 a US based Privacy Rights Clearinghouse found that only 11 out of 50 US Internet pharmacies surveyed (i.e. $22 \%$ ) complied with the necessary federal legal requirements to show that they protect

\footnotetext{
${ }^{83}$ See: http://www.antiaging-systems.com/a2z/hydergine.htm

${ }^{84}$ Currently (July 2004) the 'OffShore Pharmacy' sells various smart drugs. http://smart-drugs.net/index.html

85 Example, Saizen $\otimes$ Human Growth Hormone can be bought at http://smartdrugs.net/index.html

${ }_{86}$ Buying Drugs Online: It's convenient and private, but beware of 'rogue sites'. FDA $\begin{array}{lll}\text { Consumer } & \text { Magazine. Jan-Feb } & \end{array}$ http://www.fda.gov/fdac/features/2000/100 online.html

${ }^{87}$ Ibid

${ }^{88}$ For more information see the web site of the International Narcotics Control Board. http://www.incb.org

${ }^{89}$ INCB Annual report for 2003: $\mathrm{http}: / \mathrm{www}$.incb.org/e/ind ar.htm

${ }^{90}$ Online Pharmacies Settle FTC Charges. FTC Report, July 12, 2000.

http://www.ftc.gov/opa/2000/07/iog.htm

${ }^{91}$ M. Hochhauser, Study Finds No Privacy Rights at Many Online Pharmacies. July $9^{\text {th }}, 2004$. http://www.privacyrights.org/ar/PharmacyPrivacy.htm
} 
consumer information. ${ }^{92}$ The study also identified that $17(34 \%)$ offered some kind of privacy policy and 22 (44\%), had absolutely no privacy policy. ${ }^{93}$ While the violations by US based pharmacies are a cause for concern, even more serious are the potential for privacy breaches for Internet sites based in other parts of the world with lax privacy laws. The implications of inadequate privacy protection include the potential misuse of an individual's personal, financial or medical information for illegal activity such as spamming, identity theft and fraud among others.

\subsection{Direct to Consumer Advertising of Prescription Drugs}

Many online pharmacies advertise prescription medicines directly to consumers. This practice is legal in the US ${ }^{94}$ but prohibited in the UK/EU. ${ }^{95}$ Due to the global nature of the Internet however, potential purchasers in the UK are exposed to these advertisements. Direct to consumer advertisements may have the effect of stimulating the use of prescription drugs and other inappropriate behaviour. ${ }^{96}$ A US study in 2001, examining public information published on 104 global Internet pharmacies found that: ${ }^{97} 19 \%$ promoted prescription medicines; $23 \%$ promoted non-prescription medicines; and $23 \%$ promoted health and beauty products.

Use of direct-to-consumer advertising can intrude into the doctor-patient relationship and also cause confusion especially where promotional material (driven by commercial motives) is disguised as being educational. ${ }^{98}$ Although advertising may improve patient knowledge ${ }^{99}$, it may also result in doctors wasting time discussing patients' questions or being pressured into

\footnotetext{
${ }^{92}$ P. Wenske, Online Pharmacies put Privacy at Risk. The Kansas City Star. July 18, 2004. http://www.kansascity.com/mld/kansascity/news/consumer news/9164250.htm

${ }_{93}$ Ibid

94 The $1^{\text {st }}$ Amendment to the US constitution generally protects the advertising of prescription drugs (directly to the public) as a form of commercial speech. Advertisements are however subject to the Central Hudson Test.

95 The Medicines (Advertising) Regulations 1994 (as amended). UK Statutory Instrument 1994/1932, http://www.legislation.hmso.gov.uk/si/si1994/Uksi 19941932 en 2.htm

${ }^{96}$ T. Bessell et al, Quality of global e-pharmacies: can we safeguard consumers? Eur J Clin Pharmacol (2002) 58; 567-572.

${ }^{97}$ Ibid

${ }^{98}$ S. Wolfe, Direct-to-Consumer Advertising - Education or Emotion Promotion? N Engl J Med, Vol 346, No. 7, Feb, 14, 2002.

${ }^{99} \mathrm{P}$. Rubin, Ignorance is Death: The FDA's Advertising Restrictions, in R.D. Feldman (Ed), American Health Care, 2000.
} 
prescribing drugs that they would not necessary prescribe. ${ }^{100}$ This is particularly worrying since some studies have found that many drug advertisements are unbalanced or inaccurate. ${ }^{101,102}$

\subsection{Risks of Buying Drugs Online}

Some Internet pharmacies do not provide an address, telephone number or details to indicate where they are located. ${ }^{103} \mathrm{Also}$, an Internet site may be held on a server located in one country, using a postal address in another country and dispatching drugs from yet another country. This may result in difficulty such as: tracing a particular company if a problem develops; knowing where drugs are from; or what is in the drugs sold. ${ }^{104}$ Many of these sites may sell counterfeit drugs, or drugs containing dangerous ingredients/additives or drugs which have expired. ${ }^{105}$ As indicated earlier, consumers can be affected either directly by harmful drugs or indirectly by their condition getting worse due to ineffective drugs. ${ }^{106}$ Consumers may also suffer financial risks, such as not receiving the drugs paid for through either non-shipment or confiscation by customs authorities. ${ }^{107,108}$

\section{CHALLENGES AHEAD}

The foregoing demonstrates that many Internet Pharmacies are not socially accountable and may therefore pose a danger to consumers. This is particularly worrying since information and communication technologies provide a global market for commercial activity. While Internet Pharmacies bring some benefits, there are many problems which may arise and by extension bring regulatory challenges to authorities. These challenges, are compounded by the nature of the Internet itself. Enforcement of regulatory rules are mainly possible within a legal jurisdiction and businesses which

${ }^{100}$ M. Rosenthal et al, Promotion of prescription drugs to consumers. N Engl J Med, Vol. 346, No. 7, Feb 14, 2002.

101 D. Stryer and L Bero. Characteristics of materials distributed by drug companies: an evaluation of appropriateness. J Gen Intern Med 1996; 11:575-83.

102 M. Wilkes, B. Dobin and M. Shapiro, Pharmaceutical advertisments in leading medical journals: experts' assessment. Ann Intern Med 1992; 116:912-9.

${ }^{103}$ Supra 53

${ }^{104}$ Supra 66

${ }^{105}$ Ibid

${ }^{106}$ Ibid

${ }^{107}$ Ibid

${ }^{108}$ A study by the Austrian Federal Ministry of Social Security found that one third of all medicines ordered from 20 inline pharmacies did not arrive. Supra 36 
operate outside the scope of that legal jurisdiction present difficult problems to regulators. The nature of the Internet means that residents of one state/country are exposed to all online commerce, except where countryspecific filtering software is used to block certain sites. Internet filtering is not in widespread use for commercial Internet activity in the EU/UK and US as seen in other jurisdictions like China and Singapore. It is also unlikely that the democratic ethos of the EU/UK and US will tolerate the censoring of commercial activity on the Internet.

It is difficult or impossible for regulatory bodies to control advertising of prescription drugs from Internet sites beyond their legal jurisdiction. This is especially true for the $\mathrm{UK}$ where national rules prohibit the advertising of prescription drugs to the public unlike in the US. It is highly unlikely, however that the advertising of prescription drugs will every be made illegal in the US, due to fact that it is constitutionally protected. This therefore will continue to create a challenge to regulators in the EU/UK.

Tracing website servers which may be mobile or located in certain countries presents a major challenge to regulators. Such web sites will continue to practice regulatory arbitrage ${ }^{109}$ and hence evade enforcement action in countries like the UK and US with stricter regulatory standards compared to some other countries.

Economic considerations provide a major reason for the use of Internet pharmacies. In the US unregulated drug prices and strong patent laws have resulted in high drug costs. This has lead to many US citizens seeking cheaper sources of drugs elsewhere especially in Canada. Many US states are in favour of their citizens benefiting from low drug prices in Canada and have facilitated this, in defiance of Federal law. ${ }^{10}$ This issue continues to escalate with challenges against the US Federal Government by several states including Vermont ${ }^{111}$, Oregon ${ }^{112}$, Illinois ${ }^{13}$ and Columbia. The above

${ }^{109}$ M, Froomkin. The Internet As A Source Of Regulatory Arbitrage, 1996

http://www.law.miami.edu/froomkin/articles/arbitr.htm

${ }_{110} \mathrm{C}$, Rowland, Vt. sues over importing drugs. State challenges US after waiver of ban is denied

Globe Staff, August 20, 2004.

http://www.boston.com/business/articles/2004/08/20/vt_sues_over_importing_drugs/

${ }^{111}$ Ibid

${ }^{112}$ S, Tools, Gov pushes feds on Canadian drug imports Seeks federal waiver for effort to ease drug costs. August 2004. http://www.bend.com/news/ar view\%5E3Far id\%5E3D 17430 htm

$113 \mathrm{~J}, \mathrm{Hu}$, Illinois Web site to import cheaper drugs. CNET News.com, August 17, 2004. 
indicates that unless countries like the US consider ways of regulating domestic drug prices or changing patent laws to lower production costs, then their citizens will continue to be attracted to cheaper drug sources, especially on the Internet. This may mean that they will be exposed to drugs of poor quality and counterfeit drugs.

National governments will need to cooperate at an international level. This is because differences in national policy can be easily exploited by Internet Pharmacies wishing to engage in regulatory arbitrage. A common international regulatory approach needs to be developed to facilitate better protection for citizens in all countries, since Internet Pharmacies have a global reach.

http://news.com.com/Illinois + Web+site to timport + cheaper + drugs $/ 2100-1038$ _3-

$\underline{5313670 . \mathrm{html}}$ 